\title{
低次元化モデルを用いた原子カプラントの外乱推定
}

\author{
田嶋 真 一**若 林二 郎*
}

\section{Disturbance Estimation of Nuclear Power Plant by Using Reduced-Order Model}

\author{
Shin-ichi Tashima* and Jiro Wakabayashi*
}

An estimation method is proposed of multiplex disturbances which occur in a nuclear power plant. The method is composed of two parts: (i) the identification of a simplified model of multi-input and multi-output to describe the related system response, and (ii) the design of a Kalman filter to estimate the multiplex disturbance.

Concerning the simplified model, several observed signals are firstly selected as output variables which can well represent the system response caused by the disturbances. A reduced-order model is utilized for designing the disturbance estimator. This is based on the following two considerations. The first is that the disturbance is assumed to be of a quasistatic nature. The other is based on the intuition that there exist a few dominant modes between the disturbances and the selected observed signals and that most of the non-dominant modes which remain may not affect the accuracy of the disturbance estimator.

The reduced-order model is furtherly transformed to a single-output model using a linear combination of the output signals, where the standard procedure of the structural identification is evaded. The parameters of the model thus transformed are calculated by the generalized least square method.

As for the multiplex disturbance estimator, the Kalman filtering method is applied by compromising the following three items: (a) quick response to disturbance, (b) reduction of estimation error in the presence of observation noises, and (c) the elimination of crossinterference between the disturbances to the plant and the estimates from the Kalman filter.

The effectiveness of the proposed method

* 京都大学原子エネルギー研究所，宇治市五ケ庄

* Institute of Atomic Energy, Kyoto University, Uji (Received February 22, 1982)

(Revised October 6, 1982) is verified through some computer experiments using a BWR plant simulator.

Keyword : nuclear power plant, disturbance estimation, reduced order model, identification, Kalman filter

\section{1. 緒言}

原子力プラントなどの大規模システムにおいて, 事 故に直結するような重大な障害ではないが，長期間存 在するととにより, 故障に発展する可能性のある軽微 な異常が発生したとき，その原因となっている外乱の 種類を判別し, さらにその大きさを推定することは, その外乱を早期に取り除き，炉停止に至るような故障 を未然防止するためにも重要である. この問題にお いて筆者らは異常をいくつかのカテゴリーに分類し， あるカテゴリーに属すると判断されたものに対して, 簡単なフィルタを用いて異常の推定を行う方法を提案 した ${ }^{1,2}$. しかしながら，乙れらの方法は単一外乱代 ついて論じだものであり，ある異常が発生し，それに 対する操作を操作員が誤ったような場合や，ある異常 が発生したとき，運転状態が変化することにより，そ れまで表面にでなかった異常（たとえば，バルブの固 着等）が現れる場合をむ含めた多重異常について適用 することができなかうた，本論文では，大規模なプラ ントを多入力多出力の低次元化モデルとして同定し, このモデルに対してフィルタを構成することにより， 多重異常を含む外乱推定を行う力法について述心，計 算機シミュレーションによりその有効性を確かめた.

\section{2. 問題の設定}

プラントの外乱推定について考える.いま，プラン 卜の外乱応答を

$$
\begin{aligned}
& x(k+1)=A x(k)+B u(k) \\
& y(k)=C x(k)+D u(k)
\end{aligned}
$$

とする. 乙こで, $x \in R^{n}, u \in R^{m}, y \in R^{i}, A \in R^{n \times n}$, $B \in R^{n \times m}, C \in R^{l \times n}, D \in R^{l \times m}$ とする. さらに， 
a) (1), (2)式のシステムは, 可制御, 可観測か $\supset$ cyclic

b) 行列 $A$ 安定加正則

c) $\operatorname{rank}\left[\begin{array}{ll}A & B \\ C & D\end{array}\right]=n+m$

を仮定する．乙のとき，入力 $u$ 差分 $\tilde{u}$ を新たな入力 とするシステム

$$
\begin{aligned}
& \tilde{x}(k+1)=\tilde{A} \tilde{x}(k)+\tilde{B} \tilde{u}(k) \\
& y(k)=\tilde{C} \tilde{x}(k) .
\end{aligned}
$$

を考えると，uを状態として含むととから，(1)， （2）式における外乱推定は，(6)，（7)式における状 態推定となる：ここで

$$
\tilde{A} \triangleq\left[\begin{array}{cc}
A & B \\
0 & I
\end{array}\right], \quad \tilde{B} \triangleq\left[\begin{array}{l}
0 \\
I
\end{array}\right], \quad \tilde{C} \triangleq\left[\begin{array}{ll}
C & D
\end{array}\right], \quad \tilde{x} \triangleq\left[\begin{array}{l}
x \\
u
\end{array}\right]
$$

である. 状態推定を行う方法として, Luenberger の オブザーバや Kalman フィルタなどが考えられるが， 本論文では，外乱に対する速応性と観測雑音の影響の 低減とのトレードオフの実現の容易なことや, 最適レ ギュレータの双対であるととからフィルタ利得行列の 要素が過大となるととが少なく，プラントの特性の変 化に対して robustなととが期待できる Kalman フィ ルタを用いる. このようにして構成した外乱推定のた めのブロック線図を Fig. 1 亿示す。乙とで， $u$ は外 乱, $y$ は出力, $w$ は観測雑音. $\hat{u}$ は外乱推定量である.

いくつかの外乱とそれに対して適当に選ばれた出力 との間の入出力関係には，支配的なモードとそうでな いモードが存在する. 観測雑音が存在するため, 外乱 推定という観点からみれば，支配的でないモードはあ まり有効でないうえに推定器の次数を上げ複雑にす る。また長期間プラントに存在することにより故障に 発展する可能性のある外乱の推定を目的とすることか ら，乙こで対象之なる外乱は定常的あるいは変化の緩 やかなむのと考えるてとができる．したがって，プラ ントの比較的早いモードはほぼ定常状態に達している として直達分で近似できる.これらのととから，(1), (2) 式とし低次のモデルを用いて外乱推定を行うこと が有効でもあると考えられる，本論文では，乙の低次 元化モデルをプラントの入出力データから同定する. しかしながら，外乱を入力と考えるととから，同定の ための入出力データを実プラントの過去の運転経験や 起動試験時に得るととを考えたとき同時に複数種類の

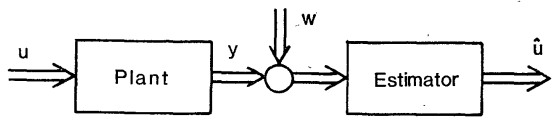

Fig. 1 Blockdiagram of disturbance estimation
外乱が生じているような場合は考え難い，乙てでは， 1 種類の外乱のみを加えたときの, 入出力データ.( $\left\{u_{i}\right.$ (k), $\left.\left.y_{i}(k), k=1,2, \cdots, N_{i}\right\}, i=1,2, \cdots, M\right)$ をいくつか 用いて， $A, B, C$ およびDを推定する. このとき, 得られたモデルが与えられた有限長のデータをよく表 わすととを目標とする. なお，低次元化モデルの次数 は，外乱推定まで含めて試行錯䛊を繰返して定める.

\section{AおよびBの推定}

一般に，多出力系の同定を行う場合，まず構造同定 という面倒な問題を解かなければならない.ところ が, Gupta らは仮定a)のもとでシステムの出力の 線形結合を新たな出力と考えるととにより，構造同定 を必要としない多出力系の同定法を提案した. 本論文 に扮いてす単一出力系に帰着させて考えるが，得られ た低次元化モデルが，与えられた入出力データを最小 2 乗の意味でよく表現するように，同定アルゴリズム として一般化最小 2 乗法を用いる.

任意の $\alpha \in R^{l}$ に対して，(1)，(2)式加ら単一出 力系

$$
\begin{aligned}
& x(k+1)=A x(k)+B u(k) \\
& z(k)=\alpha^{T} y(k)=\alpha^{T} C x(k)+\alpha^{T} D u(k)
\end{aligned}
$$

が得られる，仮定 a) から，ほとんごすべての $\alpha$ 対 して，(1)，(9)式のシステムは可観測である. 可観 測ならば，一般性を失なうことなく

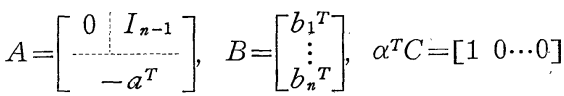

$$
\begin{aligned}
& \alpha^{T} D=b_{0}{ }^{T}, \quad a^{T}=\left[a_{n} \cdots a_{1}\right]
\end{aligned}
$$

亡することができる。乙のとき，(1)，(9)式から

$$
\begin{array}{r}
z(k+i)=\varepsilon_{i+1}{ }^{T} x(k)+\sum_{j=0}^{i} b_{j}^{T} u(k+i-j) \\
(i=0,1, \cdots, n-1) \\
z(k+n)=-a^{T} x(k)+\sum_{j=0}^{n} b_{j}^{T} u(k+n-j)
\end{array}
$$

が得られる.とこで

$$
\varepsilon_{i}{ }^{T}=[\underbrace{0 \cdots 0}_{i-1} 1: \underbrace{0 \cdots 0}_{m-i}]
$$

である. (11)，(12)式から ARMA モデル

$$
z(k+n)+\sum_{i=1}^{n} a_{i} z(k+n-i)=\sum_{i=0}^{n} \beta_{i}{ }^{T} u(k+n-i)
$$

が得られる. ARMA パラメータと(10)式の間には

$$
\left[\begin{array}{c}
\beta_{0}{ }^{T} \\
\beta_{1} T \\
\vdots \\
\beta_{n} T
\end{array}\right]=\left[\begin{array}{cccc}
1 & \ddots & & 0 \\
& \ddots & \ddots \\
a_{1} & \ddots & \ddots \\
\vdots & \ddots & \ddots \\
a_{n} & \cdots & a_{1} & 1
\end{array}\right]\left[\begin{array}{c}
b_{0}{ }^{T} \\
b_{1}{ }^{T} \\
\vdots \\
b_{n}{ }^{T}
\end{array}\right]
$$


の関係がある、いま (14)式に観測雑音を含めて簡単の ために

$$
z(k+n)=Z^{T}(k) \theta+\alpha^{T} w(k+n)
$$

と表わす。 ここで

$$
Z^{T}(k) \triangleq\left[z(k) \cdots z(k+n-1) u^{T}(k) \cdots u^{T}(k+n)\right]
$$

$$
\theta^{T} \triangleq\left[-a_{n} \cdots-a_{1} \quad \beta_{n}^{T} \cdots \beta_{0}^{T}\right]
$$

である. このとき, $\left(\left\{u_{i}(k), z_{i}(k)=\alpha^{T} y_{i}(k), k=1,2\right.\right.$, $\left.\left.\cdots, N_{i}\right\}, i=1,2, \cdots, M\right)$ に対して，一般化最小 2 乗法 を適用し， $A$ および $B$ を推定する。すなわち

a) パラメータ $\theta$ を評価関数

$$
J=\sum_{i=1}^{M} q_{i}\left(\sum_{k=1}^{N_{i}-n}\left|z_{i}(k+n)-Z_{i}^{T}(k) \theta\right|^{2}\right)
$$

が最小となるように選ぶことにより

$$
\theta=\left(\sum_{i=1}^{M} q_{i} \Omega_{i} \Omega_{i}{ }^{T}\right)^{-1}\left(\sum_{i=1}^{M} q_{i} \Omega_{i} \omega_{i}{ }^{T}\right)
$$

を得る。乙こで， $Z_{i}$ は(17)式において $\left\{u_{i}(k), z_{i}(k)\right\}$, を用いたあのであり

$$
\begin{aligned}
& \Omega_{i} \triangleq\left[Z_{i}(1) \cdots \cdots Z_{i}\left(N_{i}-n\right)\right] \\
& \omega_{i} \triangleq\left[z_{i}(n+1) \cdots \cdots z_{i}\left(N_{i}\right)\right]
\end{aligned}
$$

である。また $q_{i}$ は入出力データの組に対する重みで

$$
\begin{aligned}
& q_{i} \geq 0 \quad(i=1,2, \cdots, M) \\
& \sum_{i=1}^{M} q_{i}>0
\end{aligned}
$$

とし，同定された低次元化モデルの応答が，与えられ た入出力データにほぼ同様に一致するように $q_{i}$ を変 更し，再度同定を行うものである.

b) a)で得られた $\theta$ むとで，(16)式に打ける残 差列 $\left(\left\{e_{i}(k) \triangleq z_{i}(k)-Z_{i}{ }^{T}(k-n) \theta, k=n+1, \cdots, N_{i}\right\}\right.$, $i=1,2, \cdots, M)$ が白色雑音 $\left\{\gamma_{i}(k)\right\}$ 加ら $p$ 次の $\mathrm{AR}$ モデル

$$
e_{i}(k+p)+\sum_{j=1}^{p} \gamma_{j}{ }^{i} e_{i}(k+p-j)=v_{i}(k)
$$

で生成される有色雑音であると仮定し, 評価関数

$$
J_{i}=\sum_{k=n}^{N_{i}-p}\left|e_{i}(k+p)-E_{i}{ }^{T}(k) \gamma_{i}\right|^{2}(i=1,2, \cdots, M)
$$

を最小とするように AR パラメータ $\left(\gamma_{i}{ }^{T} \triangleq\left[\gamma_{p}{ }^{i} \cdots \gamma_{1}{ }^{i}\right]\right.$, $i=1,2, \cdots, M)$ を選ぶことにより

$$
\gamma_{i}=\left(\prod_{i} \prod_{i}{ }^{T}\right)^{-1} \prod_{i} \pi_{i}{ }^{T} \quad(i=1,2, \cdots, M)
$$

を得る.ととで

$$
\begin{aligned}
& E_{i}{ }^{T}(k) \triangleq\left[e_{i}(k) \cdots \cdots e_{i}(k+p-1)\right] \\
& I_{i} \triangleq\left[E_{i}(n) \cdots \cdots E_{i}\left(N_{i}-p\right)\right] \\
& \pi_{i} \triangleq\left[e_{i}(n+p) \cdots \cdots e_{i}\left(N_{i}\right)\right] \\
& \quad(i=1,2, \cdots, M)
\end{aligned}
$$

c） b )で求め $\gamma_{i}$ たを用いて，残差を白色化するこ とにより

$$
\begin{aligned}
& \tilde{z}_{i}(k)=z_{i}(k)+\sum_{j=1}^{p} \gamma_{j}^{i} z_{i}(k-j) \\
& \tilde{u}_{i}(k)=u_{i}(k)+\sum_{j=1}^{p} \gamma_{j}^{i} u_{i}(k-j)
\end{aligned}
$$

加ら， $\left(\left\{\tilde{u}_{i}(k), \tilde{z}_{i}(k), k=1,2, \cdots N_{i}\right\}, i=1,2, \cdots, M\right)$ を 得る.

d) . a )で求めた ARMA パラメータが収束すれば, これらの手続きを終る。収束しなければ c)で得られ たデータを用いて，a）へ戻り以上の手順を繰返す. ただし，適当な回数の繰返しの後，収束しなければ ARMA モデルの次数 $n$ を変更し, 再度同定を行う.

\section{CおよびDの推定}

与えられた有限長の入出力データをよく表現する低 次元化モデルを得ることが目的であるととから，乙こ では，前章で得られたパラメータのむとで最適な $C$ お よびDを推定する. (11)式をまとめて

$$
\bar{z}(k)=x(k)+F \bar{u}(k)
$$

と表わすととができる，ここで

$$
\begin{aligned}
& \bar{z}^{T}(k)=[z(k) \cdots \cdots z(k+n-1)] \\
& \bar{u}^{T}(k)=\left[u^{T}(k) \cdots \cdots u^{T}(k+n-1)\right] \\
& F=\left[\begin{array}{ccc}
b_{0}{ }^{T} & & \\
\vdots & \ddots & 0 \\
\vdots & \ddots & \\
b_{n}{ }^{T}-1 & \cdots & b_{0}{ }^{T}
\end{array}\right]
\end{aligned}
$$

である。これから，(2)式は

$$
y(k)=\left[\begin{array}{ll}
C & D
\end{array}\right] G \bar{Z}(k)
$$

となる.とこで

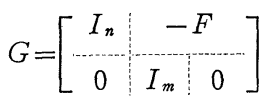

$$
\bar{Z}^{T}(k)=\left[z(k) \cdots z(k+n-1) u^{T}(k) \cdots u^{T}(k+n-1)\right]
$$

である.とのとき， $\left[\begin{array}{ll}C & D\end{array}\right]$ を評価関数

$$
J^{\prime}=\sum_{i=1}^{M} q_{i}\left(\sum_{k=1}^{N_{i}-n+1}\left|y_{i}(k)-\left[\begin{array}{ll}
C & D
\end{array}\right] G \bar{z}_{i}(k)\right|^{2}\right)
$$

が最小となるように選ぶことにより

$$
\left[\begin{array}{ll}
C & D
\end{array}\right]=\left(\sum_{i=1}^{M} q_{i} \bar{\omega}_{i} \bar{\Omega}_{i}^{T} G^{T}\right)\left(\sum_{i=1}^{M} q_{i} G \bar{\Omega}_{i} \bar{\Omega}_{i}^{T} G^{T}\right)^{-1}
$$

を得る.乙こで, $\bar{Z}_{i}$ は(37)式に扔いて $\left\{u_{i}(k), z_{i}(k)\right\}$ を用いたものであり

$$
\begin{aligned}
& \bar{\Omega}_{i}=\left[\bar{Z}_{i}(1) \cdots \cdots \bar{Z}_{i}\left(N_{i}-n+1\right)\right] \\
& \bar{\omega}_{i}=\left[y_{i}(1) \cdots \cdots y_{i}\left(N_{i}-n+1\right)\right]
\end{aligned}
$$

$$
(i=1,2, \cdots, M)
$$


である。

\section{Kalman フィルタ}

入力に積分器を仮想した $(6), （ 7)$ 式のシステムに 対して Kalman フィルタ

$$
\xi(k)=\left(I-P \tilde{C}^{T} W^{-1} \tilde{C}\right) \tilde{A} \xi(k-1)+P \tilde{C}^{T} W^{-1} y(k)
$$

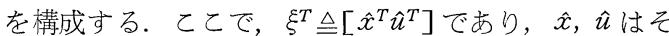
れぞれ $x, u$ の推定值である. また，Pは Riccati方 程式

$$
\tilde{A} P \tilde{A}^{T}-P-P \tilde{C}^{T}\left(W-\tilde{C} P \tilde{C}^{T}\right)^{-1} \tilde{C} P+\tilde{B} U \tilde{B}^{T}=0
$$

の正定解である. さらに，Wは正定行列，Uは非負定 行列である. このとき，Fig. 1 全体を一つのシステム としてみるとき

a） $u$ 加公にお打非干渉性

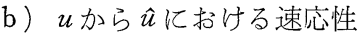

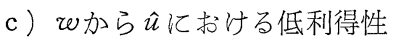

を有することが望ましい，乙とで，a）は過渡状態䎲 おいて誤って他の外乱と推定しないためであり，b) は外乱をすみやかに推定するためであり，c）は観測 雑音の影響を軽減するためである，a）から c ) の性質 を同時に満たす Kalmanフィルタを得るための，重み 行列 $U$ および $W$ を直接与える方法は見出されていな い. したがって，実際には CAD (計算機援用設計法) などを用いて，試行錯誤法により適当な重み行列 $U お$ よびWを探索するむのとする.

\section{6. 例 題}

上述の方法の有効性を確かめるために，計算機シミ ュレーションを行った. 対象としたシステムは, Fig.2 に示す BWR (Boiling Water Reactor) プラントモ デルであり，非線形 31 次微分方程式で記述されてい る. 外乱として, バイパス弁蒸気漏れ $b$ （主蒸気流量 定格值の $0 \sim 10 \%$ ), 負荷要求変動 $l$ (定格値の $0 \sim 20$ \%減少)，反応度異常 $\rho(-0.065 \% \sim+0.065 \%) の$ 3 種類を考え

$$
u^{T}=\left[\begin{array}{lll}
b & l & \rho
\end{array}\right]
$$

とする. 多数のプロセス信号の中から，物理的考察の 結果, 観測信号として, 中性子束密度 $n$, タービン入口 左力 $p$, 主蒸気流量 $f$, 再循環流量制御信号 $r$ を選び

$$
y^{T}=\left[\begin{array}{llll}
n & p & f & r
\end{array}\right]
$$

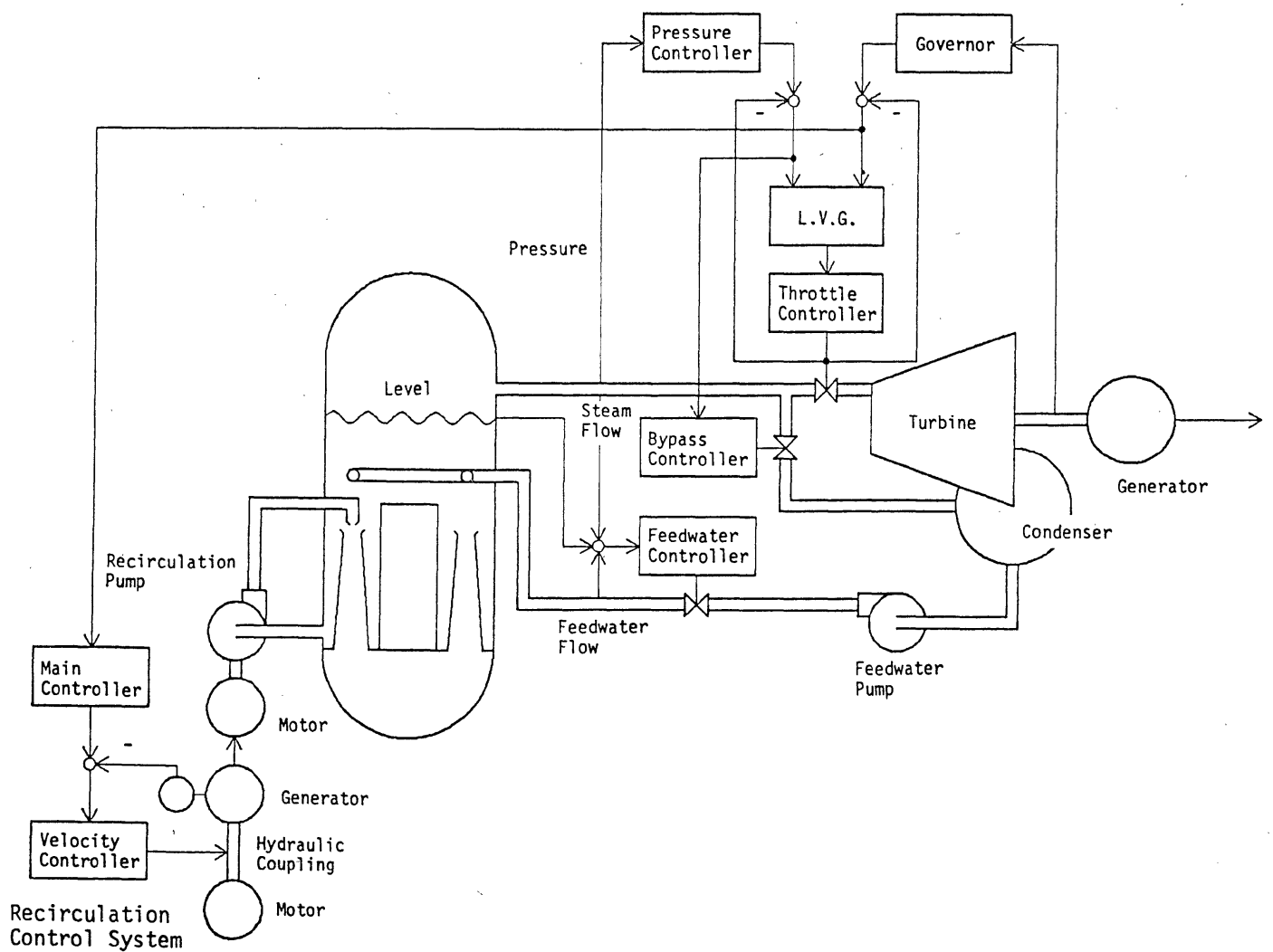

Fig. 2 Boiling Water Reactor (BWR) model 
とする．乙のモデルを用いて 300 秒間のシミュレーシ ヨンを行い， 0.3 秒ごとに 1000 点のデータを得た. と こで外乱として

$$
\begin{aligned}
& u_{i}(t)= \begin{cases}\bar{u}_{i}(t / 50) & (t \leq 50) \\
\bar{u}_{i} & (t>50)\end{cases} \\
& \bar{u}_{1}^{T}\left[\begin{array}{lll}
-5 & 0 & 0
\end{array}\right], \quad \bar{u}_{2}^{T}=\left[\begin{array}{lll}
0 & -10 & 0
\end{array}\right], \\
& \bar{u}_{3}^{T}=\left[\begin{array}{lll}
0 & 0 & 0.065
\end{array}\right]
\end{aligned}
$$

を用いた. このデータに対して

$$
\begin{aligned}
& \alpha^{T}=\left[\begin{array}{llll}
1 & 1 & 1 & 1
\end{array}\right] \\
& q^{T}=\left[\begin{array}{lll}
q_{1} & q_{2} & q_{3}
\end{array}\right]=\left[\begin{array}{lll}
1 & 1 & 100
\end{array}\right]
\end{aligned}
$$

を用いて, まず, 出力の数程度の次数として 4 次のモ デルで同定を行った. とのとき，3章の一般化最小 2 乗法の繰返しによる ARMA パラメータの変化を Fig. 3 に示す. ここで各パラメータは 20 回の繰返し の後の值で正規化してある. このパラメータから低次 元化モデル

$$
\begin{aligned}
A & =\left[\begin{array}{cccc}
0 & 1 & 0 & 0 \\
0 & 0 & 1 & 0 \\
0 & 0 & 0 & 1 \\
-2.735 \times 10^{-1} & 1.347 & -2.854 & 2.779
\end{array}\right] \\
B & =\left[\begin{array}{rrr}
-7.521 \times 10^{-2} & -5.707 \times 10^{-4} & 31.88 \\
7.521 \times 10^{-4} & 1.259 \times 10^{-2} & -1.083 \\
3.187 \times 10^{-2} & 2.403 \times 10^{-2} & -11.06 \\
3.082 \times 10^{-2} & 3.376 \times 10^{-2} & -10.10
\end{array}\right]
\end{aligned}
$$$$
C=\left[\begin{array}{ll}
-39.15 & \multicolumn{1}{c}{99.80} \\
2.804 \times 10^{-1} & -7.688 \times 10^{-1} \\
21.50 & -56.78 \\
18.36 & -42.25
\end{array}\right.
$$$$
\left.\begin{array}{cc}
-90.89 & \multicolumn{1}{c}{30.81} \\
7.572 \times 10^{-1} & -2.629 \times 10^{-1} \\
54.57 & -19.17 \\
35.56 & -11.38
\end{array}\right]
$$$$
D=\left[\begin{array}{rrr}
-9.966 \times 10^{-1} & -1.133 & 1108 \\
3.387 \times 10^{-2} & -1.829 \times 10^{-4} & -5.176 \\
4.785 \times 10^{-1} & 5.324 \times 10^{-1} & -482.1 \\
4.520 \times 10^{-1} & 6.022 \times 10^{-1} & -461.5
\end{array}\right]
$$

が得られた. このシステムに対して, Kalman フィル タが 5 章で述べた a)－c）の性質を有するように重み 行列 $U, W$ 対角行列の範囲で探索の結果

$$
\begin{aligned}
U & =\operatorname{diag}\left[3 \times 10^{-4}, 10^{-3}, 3 \times 10^{-7}\right] \\
W & =\operatorname{diag}\left[10,10^{-3}, 10,10\right]
\end{aligned}
$$

として Kalmanフィルタを構成し，乙れを用いて多重 外乱

$$
\begin{aligned}
& u_{d i}= \begin{cases}\bar{u}_{d i}(t / 50) & (t \leq 50) \\
\bar{u}_{d i} & (t>50)\end{cases} \\
& \bar{u}_{d 1} T=\left[\begin{array}{ll}
-50-0.039 &
\end{array}\right.
\end{aligned}
$$

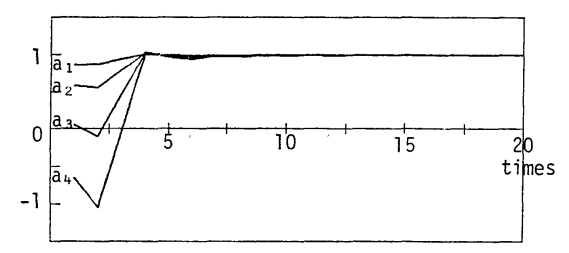

(a) Entries of $a$

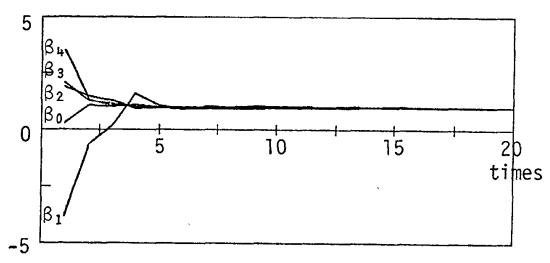

(b) 1st entries of $\beta_{i}$

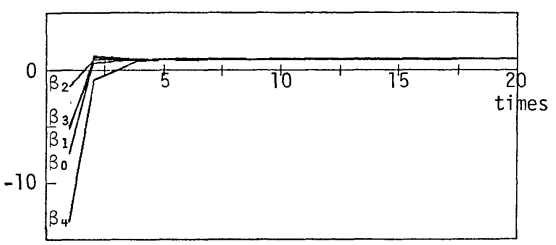

(c) 2nd entries of $\beta_{i}$

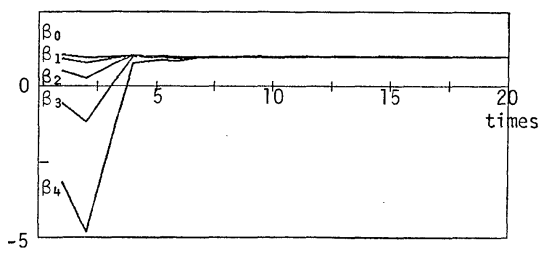

(d) 3rd entries of $\beta_{i}$

Fig. 3 Convergence of ARMA parameters

$$
\begin{aligned}
& \bar{u}_{d 2^{T}}=\left[\begin{array}{lll}
0 & -10 & -0.039
\end{array}\right], \\
& \bar{u}_{d 3^{T}}=\left[\begin{array}{lll}
-5 & -10 & 0
\end{array}\right]
\end{aligned}
$$

のシミュレーションデータについて外乱推定を行った 結果を Fig. 4〜6に示す. こてで，細線は外乱を，太 線はその推定值を表わす. また, 観測雑音として実際 の測定機器の雑音を考慮し, 平均 0 , 分散

$$
\Sigma=\operatorname{diag}\left[3^{2}, 0.2^{2}, 1^{2}, 1^{2}\right]
$$

の白色雑音を仮定した. これらの眓から, 外乱の範囲 および変化の速度と観測雑音の大きさを考慮すれば, ほぼ，5章で述べた a )からc)の性質をむつ外乱推定 器が得られたととがわかる，とのことは，3，4 章の 方法によって，十分によい低次元化モデルが得られた ことを示している. したがって低次元化モデルの次数 は4 次のままとした. 以上から，乙てで述べた外乱推 定器の構成法は十分に有効である.

\section{7. 結言}

多出力系の出力の線形結合を新たな出力と考えるこ 


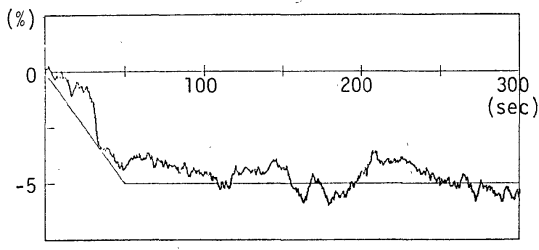

(a) Bypass leak

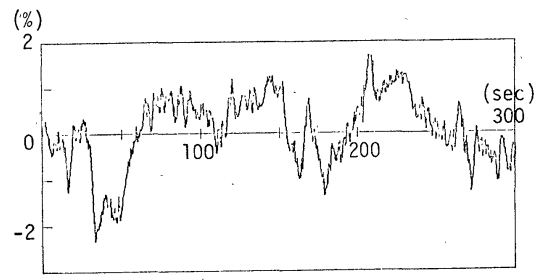

(b) Load demand

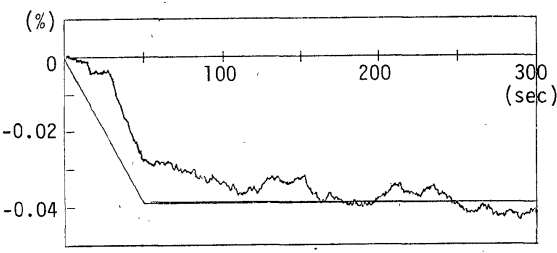

(c) Reactivity

Fig. 4 Simulation results of disturbance estimation (disturbances: bypass leak and reactivity)

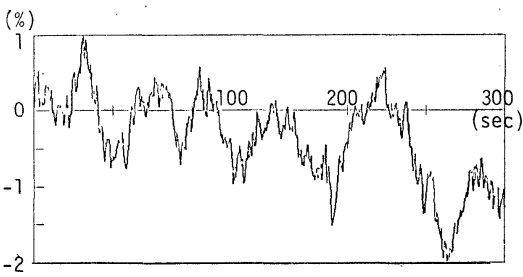

(a) Bypass leak

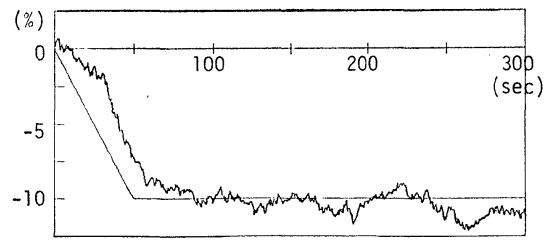

(b) Load demand

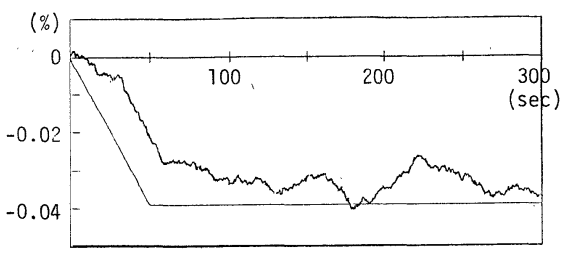

(c) Reactivity

Fig. 5 Simulation results of disturbance estimation (disturbances: load demand and reactivity)

とにより，単一出力系とするととができる．乙れを用

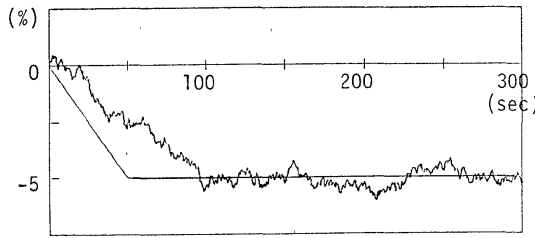

(a) Bypass leak

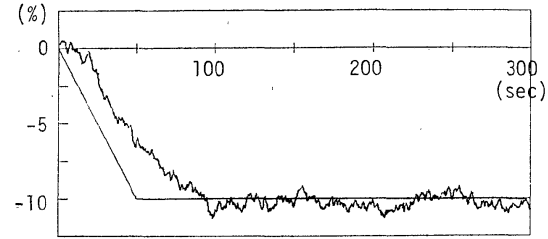

(b) Load demand

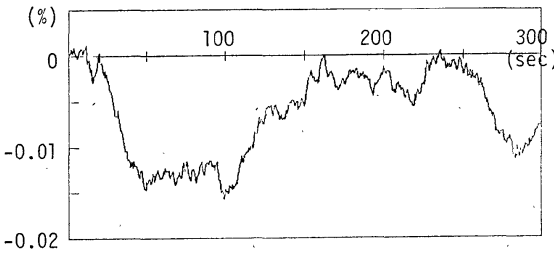

(c) Reactivity

Fig. 6 Simulation results of disturbance estimation (disturbances: bypass leak and load demand)

いることにより，構造同定を必要としない多出力系の 同定手法が得られる，本論文では，直達分を考慮した モデルに対して，一般化最小 2 乗法を適用して， $A$ ，

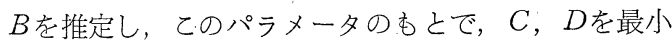
2 乗法を用いて推定することにより低次で精度のよい モデルが得られた．乙の手法を用いて，数多くのプラ ント入出力データから推定されるプラントの低次元化 モデルの, 入力側に積分器在付加したシステムに対し て Kalmanフィルタ形の推定器を構成し，乙れを用い て多重外乱を含めた外乱推定を行う方法を扱い，例題 により，その有効性を確かめた。

最後に，例題に用いた BWR プラントシミュレー 夕作成にあたり，有益な助言をいただいた盛岡俊彦， 田辺章画氏（東京芝浦電気(株)）に謝意を表します.

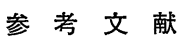

1) J. Wakabayashi, A. Fukumoto, S. Tashima and I. Kawahara: Application of Adaptive Kalman Filtering Technique for the Diagnostic System of Nuclear Power Plants, Proc. 19th IEEE Conf. on Decision and Control, 1, 127/132 (1980)

2) J. Wakabayashia and A. Fukumoto: Simulation Study of a System for Diagnosis of Nuclear Power Plant Operation, Nuclear Tech., 54-1, 19/30

3) R. D. Gupta and F. W. Fairman: Parameter Estimation for Multivariable Systems, IEEE Trans. on Automatic Control, AC-19-5, 546/549 (1974) 